\title{
High Energy Phosphate Compounds in the Myocardium during Experimental Congestive Heart Failure. Purine and Pyrimidine Nucleotides, Creatine, and Creatine Phosphate in Normal and in Failing Hearts *
}

\author{
Arthur C. Fox, Norman S. Wikler, and George E. Reed \\ (From the Departments of Medicine and Surgery, New York University School of Medicine, \\ New York, N. Y.)
}

High energy phosphate compounds are generally considered essential for muscular contraction although it is not clear how their chemical energy is ultimately made available for transformation into mechanical work (1-3). According to classical concepts, hydrolysis of adenosine triphosphate (ATP) by myofibrillar ATPase (adenosine triphosphatase) occurs at some time during repetitive cycles of muscular contraction and relaxation, and as a result adenosine diphosphate (ADP) is produced. Delivery of this ADP to mitochondria for regeneration into ATP can serve as an important regulator of the activity of mitochondrial oxidative phosphorylation (4, $5)$. In failing hearts, changes in oxidative phosphorylation or its products might accordingly reflect primary changes at the mitochondria or altered delivery of ADP from the failing myofibrils (6).

Many studies of normal and failing hearts have examined the processes involved in the formation and utilization of high energy phosphate compounds (7). During spontaneous heart failure in man $(8-10)$ and induced heart failure in dogs (11), there were no significant changes in uptake by the myocardium of oxygen or of the diverse substrates from which chemical energy is liberated and then conserved as nucleoside triphosphates or as creatine phosphate ( $\mathrm{CrP})$. However, small, long-term, or localized alterations in uptake of exogenous substrates might not have been detected by acute measurements of arteriovenous

* Submitted for publication December 19, 1963; accepted October 15, 1964.

Supported by grant H-3312 from the National Institutes of Health, U. S. Public Health Service. differences across intact hearts in situ (12). Concentrations of high energy phosphates have been reported to be normal in isolated, acutely failing dog hearts, guinea pig atria, and cat papillary muscles (13-15) and in chronically failing hearts from dogs with tricuspid insufficiency and pulmonary stenosis or with aortic insufficiency $(11,16)$. Muscle preparations from failing canine and human hearts have shown decreased contractility $(17,18)$ and decreased ATPase activity (19), but myofibrillar proteins from failing canine hearts have been reported to be both normal (20) and altered (21).

Recently, changes have been observed in the morphology of mitochondria from failing hearts of dogs with aortic stenosis (22) and in the metabolic responses of mitochondria from failing hearts of guinea pigs with aortic stenosis (23, 24). Improved methods for isolation, separation, and specific assay of high energy phosphate compounds have made possible more precise measurements of tissue levels of these labile compounds (25-27). With the use of such improved techniques, a recent study found significant decreases in levels of ATP, $\mathrm{CrP}$, and creatine $(\mathrm{Cr})$ in failing hearts from guinea pigs with aortic stenosis (28). Since the status of labile phosphate compounds in the chronically failing heart did not yet seem settled, it was considered pertinent to re-examine the content of purine and pyrimidine nucleotides and $\mathrm{CrP}$ in hearts from dogs with unequivocally severe, chronic, low output cardiac failure.

This report deals with the production of chronic congestive heart failure in dogs and with measurement of the levels of purine and pyrimidine 
nucleotides, $\mathrm{Cr}$, and $\mathrm{CrP}$ in the right and left ventricles from the hearts of these animals. There were significant decreases in concentrations of $\mathrm{ATP}, \mathrm{Cr}$, and $\mathrm{CrP}$ in severely stressed right ventricles from hearts in chronic failure due to pulmonary arterial stenosis. ${ }^{1}$

\section{Methods}

Production of congestive heart failure in dogs. Two methods that have been widely used for the production of chronic congestive heart failure in dogs were examined further. Fourteen dogs were subjected to a combination of tricuspid insufficiency and pulmonary arterial stenosis (29). Severe tricuspid insufficiency was produced by avulsion of all tricuspid chordae tendineae except those of the septal leaflet; 2 weeks later, as much transverse area of the main pulmonary artery was resected as the animal could tolerate (usually 70\%). In 17 animals, isolated, severe stenosis of the main pulmonary artery was successfully produced by the method of Davis, Hyatt, and Howell (30). Ligatures placed around the main pulmonary artery were progressively tightened at weekly intervals to maintain right ventricular systolic pressures of at least 75 to $100 \mathrm{~mm} \mathrm{Hg}$. When breathlessness, ascites, edema, and engorgement of the liver appeared, chest $\mathrm{X}$ rays were taken to demonstrate cardiac enlargement, and hemodynamic studies were performed by right heart catheterization. A basal state was assured by light thiopental anesthesia, and adequate spontaneous oxygenation was maintained through a cuffed endotracheal tube. The hemodynamic criteria for heart failure included the presence of marked elevations of right ventricular end diastolic pressure, measured at the trough of the transmitted $a$ wave, and significant increases in a-v $\mathrm{O}_{2}$ difference. Animals with evidence of severe anemia, malnutrition, infection, or pulmonary infarction were discarded.

Right ventricular hypertrophy without congestive heart failure was produced with pulmonary arterial ligatures that were tightened sufficiently to cause sustained elevations in right ventricular systolic pressures without increases in the end diastolic pressures or in a-v $\mathrm{O}_{2}$ differences.

1 The principal abbreviations used in this report are as follows: AMP, ADP, ATP, GMP, GDP, GTP, UMP, UDP, UTP $=$ the $5^{\prime}$ mono-, di-, and triphosphates of adenosine, guanosine, and uridine; CMP, CTP $=$ the $5^{\prime}$ mono- and triphosphates of cytidine; IMP $=$ the $5^{\prime}$ monophosphate of inosine; NAD = nicotinamide adenine dinucleotide $(\mathrm{DPN}) ; \mathrm{FAD}=$ flavin-adenine dinucleotide ; $\mathrm{Cr}=$ creatine $\mathrm{CrP}=$ creatine phosphate; $\mathrm{P}_{1}=$ inorganic phosphate; $\mathrm{TASP}=$ total acid-soluble phosphate; $\mathrm{A} 260=$ absorbance of ultraviolet (UV) light at $260 \mathrm{~m} \mu$; a-v $\mathrm{O}_{2}$ difference $=$ the difference in oxygen content between femoral arterial and mixed venous blood from the right ventricle or the pulmonary artery.
Rapid extirpation of normal, hypertrophied, or failing hearts was effected while the hearts were beating or immediately after induction of cardiac arrest. The chests were opened during gentle, assisted respiration with oxygen, and pressures in the right and left ventricles of the failing hearts were measured by direct puncture of the two chambers. Arrest was produced by rapid injection into the cross-clamped aorta of $5 \mathrm{ml}$ of $5 \%$ potassium citrate at $\mathrm{pH} 9$ (31). Fewer than 3 to $5 \mathrm{QRS}$ complexes occurred between the beginning of the injection and total arrest. The cardiac apex was grasped with a sharp towel clip, the atria and great vessels were quickly severed, and the intact ventricles were plunged into a Dewar flask filled with liquid nitrogen. The procedure rarely exceeded 6 seconds; specimens were discarded if extirpation and freezing took more than 10 seconds. In five studies, the quadriceps femoris muscle was exposed without damage to its blood supply and was rapidly excised and frozen as the aorta was clamped or as the beating heart was excised.

Acid-soluble extracts of the muscle specimens were prepared in a cold room at $4^{\circ} \mathrm{C}$. The free walls of both ventricles were rapidly separated and fragmented. The frozen fragments were chipped clean of visible blood vessels, visceral pericardium, fat, fibrous tissue, and adherent blood, and pulverized to a fine powder under liquid nitrogen in a large porcelain mortar. The powdered muscle was rapidly mixed into cold, $0 / 6 \mathrm{~N}$ perchloric acid, and homogenized at $45,000 \mathrm{rpm}$ for $15 \mathrm{~min}-$ utes with a VirTis model 45 tissue homogenizer. The acid extract was separated in a centrifuge at $4^{\circ} \mathrm{C}$ and $25,000 \mathrm{~g}$. The clear supernatant fluid was combined with centrifuged water washings of the precipitate and neutralized in an ice bath with $5 \mathrm{~N} \mathrm{KOH}$ to $\mathrm{pH}$ 7.0. Partial freezing precipitated $\mathrm{KClO}_{4}$, which was removed by filtration. The volume of the filtrate was measured and its content of material absorbing at $260 \mathrm{~m} \mu$ (A260) determined; then it was stored at $-20^{\circ} \mathrm{C}$ until analyzed.

Fat-free, dry weights were determined for each muscle sample to correct for variations in water and fat content (32). Since significant increases in collagen content had not been found in human hearts failing from a wide variety of causes (33), corrections for collagen content were not made.

Separation and measurement of the nucleotides in extracts of normal and failing hearts were achieved by gradient elution from Dowex 1 (C1) X-10 resin columns (25), which were $20 \times 1.25 \mathrm{~cm}$ in size. Between $90 \%$ and $95 \%$ of the A260 material in the extracts was regularly absorbed by the resin. Compressed air was used to force eluting solutions of increasing concentrations of formic acid and ammonium formate through a mixing flask and then through the columns, which were encased in a tap water jacket. Serial 5-ml fractions were collected by a Technicon fraction collector with a dropcounting attachment, and the A260 of each fraction was read in a Beckman DU spectrophotometer. The eluates comprising each significant peak of UV absorbancy were dried on a VirTis freeze-dryer to remove eluting salts 
that interfered with accurate spectrophotometric analysis. The dried nucleotide powders were dissolved in known volumes of water, identified by their absorption spectra at $\mathrm{pH} 1$, and quantitated by measurement of absorbancy at their absorption maxima and by application of standard molar absorbancy indexes. Precise identification of NAD was obtained by demonstration of its UV spectrum shift with cyanide, and of FAD by its migration and fluorescence in paper chromatograms. Further separation of compounds that were not well isolated by the formic acid system was effected by Phase II chromatography on Dowex 1 resin columns $8 \times 1 \mathrm{~cm}$ in size. Eluates were obtained with concentration gradients of ammonium formate buffer at $\mathrm{pH} 5$.

The technique was standardized by elution from the resin columns of pure nucleotides mixed in amounts anticipated for $25 \mathrm{~g}$ of heart muscle. Average recovery rates of significant compounds were as follows: ATP, 98\%; ADP, 95\%; NAD, 87\%; IMP, 96\%, CTP, 88\%; CMP, $94 \%$. Recovery rates of several compounds were artificially increased by breakdown of the more concentrated and labile nucleoside triphosphates: AMP, $111 \%$; UMP, $122 \%$; GDP, $112 \%$. UDP was variably recovered at about $50 \%$. Measurements of nucleotides in duplicate specimens from the same ventricle yielded values that agreed within 5\%. Because it was difficult to remove completely the concentrated ammonium formate salts added during Phase II separation of UTP and GTP, recoveries were estimated directly from the UTP and GTP peaks in the Phase II chromatograms. Since these recovery rates were only $50 \%$, the values subsequently found for UTP and GTP in tissues were doubled to give a better approximation of in vivo levels. The identity of each compound isolated from the columns in the early part of the study was confirmed by paper chromatography in two directions (34). Quantitative elutions from paper of the principal separated nucleotides did not yield recoveries equal to those obtained with the resin-spectrophotometric system.

Total acid-soluble phosphate was measured in samples of the muscle extracts after all bound phosphates were hydrolyzed by $5 \mathrm{~N} \mathrm{H}_{2} \mathrm{SO}_{4}$ in an oil bath heated at $160^{\circ} \mathrm{C}$ for 1 hour. The liberated phosphate was measured (35) with standard recovery rates of $95 \%$. This procedure was also used early in the study to confirm the spectrophotometric quantitation of eluted, dried nucleotides; the results obtained by the two methods checked regularly within 5\%. Analysis of $\mathrm{CrP}$, ATP, and ADP by measurement of the phosphate liberated by selective hydrolysis of CrP and "acid labile" nucleotide phosphates ("p-p") (35) did not prove as reliable as the ion exchange method.

Creatine phosphate was measured by two methods. The method of Furchgott and De Gubareff (36) depends upon measurement of free inorganic phosphate and then of additional phosphate liberated by carefully controlled acid hydrolysis of $\mathrm{CrP}$. The method of Ennor and Rosenberg (37) measures the colored diacetyl compound formed first with free creatine base and then with the additional creatine base liberated by acid hydrolysis of $\mathrm{CrP}$. These procedures also yielded values for inorganic phosphate and for free and total creatine. The methods were standardized by analysis of known mixtures of $\mathrm{Cr}, \mathrm{CrP}$, and $\mathrm{P}_{1}$ and were found to be accurate within $5 \%$. Addition of contaminating ATP did not affect the accuracy of the standard measurements.

\section{Results}

\section{Evaluation of the severity of congestive heart failure}

Tricuspid insufficiency and pulmonary arterial stenosis, as combined lesions, produced ascites in only six of 14 animals despite frequent exercise on a treadmill, and animals with severe ascites could exercise well. Spontaneous diureses occurred frequently, with abrupt disappearance of ascites. Even when severe circulatory congestion had been present for periods of from 3 to 10 months, mean right atrial pressures ranged from 11 to $15 \mathrm{~mm} \mathrm{Hg}$, right ventricular systolic pressures were only 22 to $45 \mathrm{~mm} \mathrm{Hg}$, and right ventricular end diastolic pressures were from 4 to $10 \mathrm{~mm} \mathrm{Hg}$. Values for a-v $\mathrm{O}_{2}$ differences never exceeded 6 vol per $100 \mathrm{ml}$.

Progressive pulmonary arterial stenosis was a more reliable method for producing severe congestive heart failure. Many animals with tightened ligatures died in failure before studies could be completed. Systolic pressures in the right ventricle had been markedly elevated for as long as 6 weeks before signs of congestive heart failure appeared. End diastolic pressures were seldom elevated before the appearance of severe ascites, hepatic engorgement, leg edema, and pleural effusions. Breathlessness at rest and significant increases in $\mathrm{a}-\mathrm{v} \mathrm{O}_{2}$ difference were the last changes to appear. When there was severe congestive heart failure, pressure gradients across the stenosed pulmonary arteries remained high, although systolic pressures in the right ventricles had fallen by as much as $30 \%$ from peak levels. Ventricular alternans was sometimes present. The contours of the right atrial pressure curves did not reflect the severe degree of tricuspid regurgitation apparent in exposed hearts. The right ventricles were markedly dilated and hypertrophied. The oxygen contents and saturations of femoral arterial blood indicated that although some animals were mildly anemic, all were well 
TABLE I

Hemodynamic measurements

\begin{tabular}{|c|c|c|c|c|c|c|c|c|c|}
\hline \multirow[b]{3}{*}{$\underset{\text { no. }}{\text { Animal }}$} & \multirow{3}{*}{$\begin{array}{c}\text { Days } \\
\text { with } \\
\text { pulmo- } \\
\text { nary } \\
\text { stenosis }\end{array}$} & \multicolumn{4}{|c|}{ Intracardiac pressures } & \multicolumn{4}{|c|}{ Blood gases } \\
\hline & & \multicolumn{2}{|c|}{ By catheter } & \multirow{2}{*}{\multicolumn{2}{|c|}{ 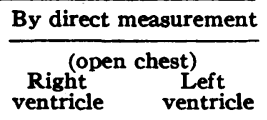 }} & \multirow{2}{*}{$\begin{array}{l}\text { Arterial } \\
\text { oxygen } \\
\text { satura- } \\
\text { tion }\end{array}$} & \multirow[b]{2}{*}{$\begin{array}{c}\text { Arterial } \\
\text { oxygen } \\
\text { content }\end{array}$} & \multirow{2}{*}{$\begin{array}{l}\text { Mixed } \\
\text { venous } \\
\text { oxygen } \\
\text { content }\end{array}$} & \multirow[b]{2}{*}{$\begin{array}{c}\text { a-v } \mathrm{O}_{2} \\
\text { differ- } \\
\text { ence }\end{array}$} \\
\hline & & $\begin{array}{l}\text { Right } \\
\text { atrium } \\
\text { (mean) }\end{array}$ & $\begin{array}{c}\text { Right } \\
\text { ventricle }\end{array}$ & & & & & & \\
\hline & & $m m \mathrm{Hg}$ & $m m \boldsymbol{H g}$ & $m m H g$ & $m m \mathrm{Hg}$ & $\%$ & $20 l / 100 \mathrm{ml}$ & $00 \mathrm{l} / 100 \mathrm{ml}$ & $20 l / 100 \mathrm{ml}$ \\
\hline & & & A. Animals & ere heart $f$ & Ire produce & almonary & arterial liga & ures & \\
\hline \multirow{2}{*}{1} & \multirow{2}{*}{17} & \multirow{2}{*}{9} & 71 & 62 & 94 & \multirow{2}{*}{95} & \multirow{2}{*}{17.29} & \multirow{2}{*}{7.94} & \multirow{2}{*}{9.35} \\
\hline & & & $-3,14$ & 8,14 & 8,11 & & & & \\
\hline \multirow{2}{*}{2} & \multirow{2}{*}{57} & \multirow{2}{*}{13} & 74 & 70 & 117 & \multirow{2}{*}{96} & \multirow[b]{2}{*}{16.5} & \multirow[b]{2}{*}{9.6} & \\
\hline & & & 0,18 & 6,17 & 4,7 & & & & 7.2 \\
\hline 3 & & & 64 & 110,57 & 120 & & & & \\
\hline 3 & 74 & 19 & 0,11 & $\overline{10,17}$ & 6,12 & & 13.7 & 6.42 & 6.65 \\
\hline & & & 77 & 73 & & & & & \\
\hline 4 & 60 & 15 & $-5,15$ & $\overline{1,11}$ & & 100 & 16.15 & 5.36 & 10.97 \\
\hline 5 & & & 96 & 92 & & & & & \\
\hline 3 & 80 & 11 & 8,14 & 7,14 & & 101 & 19.44 & 11.97 & 7.47 \\
\hline 6 & 36 & & 79 & 100 & 100 & & & & \\
\hline 0 & 30 & 13 & 0,13 & 3,8 & 1,6 & 102 & 20.67 & 10.82 & 9.85 \\
\hline 7 & 19 & 16 & 58 & 53 & 105 & & & & \\
\hline ( & 19 & 10 & 10,20 & $\overline{1,13}$ & $-4,7$ & & 15.50 & 8.54 & 6.96 \\
\hline & & & 99 & 113 & & & & & \\
\hline 8 & 90 & 15 & 4,22 & 8,25 & & & 20.14 & 10.13 & 9.83 \\
\hline & & & 96 & 52 & 68 & & & & \\
\hline 9 & 40 & 11 & $-2,13$ & 2,7 & $-1,2$ & 102 & 16.39 & 8.36 & 8.03 \\
\hline 10* & 39 & 11 & 97 & 64 & 91 & 100 & 1301 & 601 & 605 \\
\hline 10 & 39 & 11 & 2,17 & 5,13 & 3,6 & 100 & 13.91 & 0.91 & 0.95 \\
\hline 11 & 41 & 16 & 75 & 75 & 100 & 105 & 1263 & 562 & 709 \\
\hline 11 & $\mathbf{4 1}$ & 10 & $-4,14$ & $\overline{0,14}$ & 0,4 & 100 & 12.03 & 3.02 & 1.01 \\
\hline $112 *$ & 100 & 15 & 75 & 95 & 89 & 90 & & & \\
\hline $11 d^{-2}$ & 100 & 10 & 2,18 & $\overline{5,25}$ & 0,4 & 99 & 20.44 & 8.26 & 12.2 \\
\hline 12 & 34 & & 65 & 53 & 70 & & & & \\
\hline 12 & 34 & 11 & 1,2 & 2,7 & 0,4 & 99 & 17.79 & 11.01 & 6.8 \\
\hline 13 & 20 & 10 & 53,68 & 68,89 & 110,112 & & & & \\
\hline 13 & 29 & 10 & 5,10 & $\overline{12,12}$ & 3,4 & 102 & 15.50 & 7.97 & 7.53 \\
\hline 11 & 37 & & 40 & 60 & 75 & & & & \\
\hline 14 & 37 & 14 & $-2,14$ & $\overline{5,12}$ & 1,3 & 100 & 9.97 & 2.24 & 7.73 \\
\hline & & & 87 & & & & & $-a$ & \\
\hline 15 & 36 & 15 & 7,11 & & & 94 & 14.7 & 5.8 & 8.9 \\
\hline 16 & 32 & 14 & 68 & & & 1 & & & \\
\hline 10 & $8=$ & 14 & 0,17 & & & 103 & 16.63 & 10.01 & 6.62 \\
\hline 17 & 40 & 14 & 72 & & & 100 & 15.23 & $0 ?$ & 60 \\
\hline & & & 2,16 & & & 100 & 15.23 & 9.2 & 6.0 \\
\hline Average & 48 & 13 & 76 & 77 & 95 & 100 & 163 & 81 & $8 ?$ \\
\hline Average & 40 & 10 & 2,14 & 5,14 & 2,6 & 100 & 10.3 & 8.1 & 8.2 \\
\hline
\end{tabular}


TABLE I-Continued

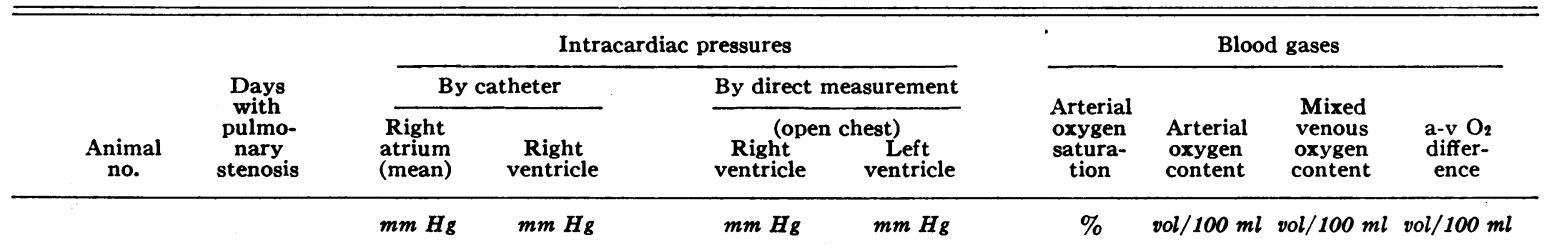

B. Animals with pulmonary arterial ligatures and chronic right ventricular hypertrophy without heart failure

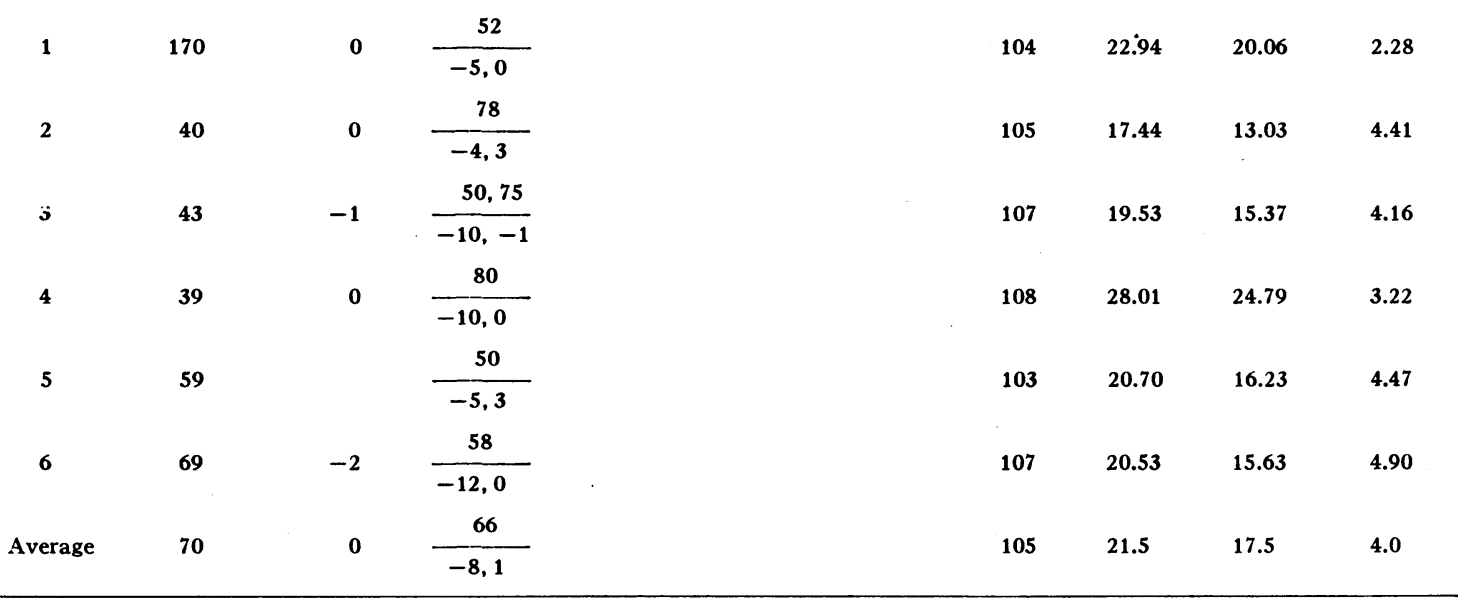

* Not examined chemically.

oxygenated. With thoracotomy, systolic pressures in both ventricles fell slightly (38); end diastolic pressures were uniformly high in the right ventricles, but remained normal or were only slightly elevated in the left ventricles. Hearts 10 and $11 \mathrm{~A}$ were discarded because their extirpation was too slow (Table I, A).

Right ventricular hypertrophy was evident in the chest $\mathrm{X}$ rays and exposed hearts of six animals in which a constant degree of pulmonary arterial stenosis and right ventricular systolic hypertension had been present for long periods. No clinical or hemodynamic evidence for heart failure was present in these animals. The need for expeditious handling precluded weighing or precise measurement of the hearts, but the thickness of the right ventricular walls, estimated by gross inspection of the frozen, transected specimens, certainly equaled that present in the failing hearts. Arterial oxygen saturations were high in this group, as they often were in the failure and control groups (Table I, B).

\section{Nucleotide content}

Qualitative. The qualitative patterns found for right and left ventricles from each normal and failing heart were identical; no analyses for nucleotides were made in the hypertrophied control groups. Compounds identified by ion exchange chromatography, UV absorption spectra, and paper chromatography included NAD, CMP, AMP, IMP, UMP, FAD, UDP, GDP, CTP, ATP, UTP, and GTP (Figure 1). The small "ADP." peak that tailed after the principal ADP peak was shown by its UV spectrum and $R_{f}$ value to consist primarily of $A D P$ and was included in the quantitative values for ADP. Adequate resolution of the IMP/UMP peak was rarely possible, and much of this material probably represented degradation products from other nucleotides.

The 5 to $10 \%$ of A260 material in the acidsoluble extracts that did not adsorb on the resin columns was not clearly defined. Paper chromatography of this fraction showed that it did not contain nucleotides; its elution characteristics and absorption spectrum resembled those of inosine.

A normal human myocardium yielded a nucleotide pattern qualitatively similar to that shown for the canine right ventricle in Figure 1. Fifteen minutes after ventricular fibrillation had been induced by penal electrocution of a 30 -year-old 
healthy man, the anatomically normal heart was removed and frozen in liquid nitrogen. Despite considerable hydrolysis of the labile nucleoside triphosphates during the delay in tissue sampling, the following compounds were clearly identified in right and left ventricles: inosine, CMP, NAD, AMP, UMP, ADP, GDP, ATP, UTP, and GTP.

Quantitative. The total amount of A260 material in the neutralized acid-soluble extracts of normal and failing hearts was variable and not a reliable index of nucleotide content. Of the total nucleoside triphosphates in normal ventricles, ATP comprised 92 to $94 \%$, reflecting the importance of this compound in myocardial energy metabolism; CTP, UTP, and GTP comprised the remaining 6 to $8 \%$ (Table II). Of the total adenine nucleotides, ATP comprised $84 \%$ in both ventricles. There were no significant differences in nucleotide content between normal left and right ventricles, whether the values found were compared statistically as pairs or as groups.

Among the eight failing hearts, the ratio between wet and dry tissue weights was increased by an average of $3 \%$ for the left ventricles and by $5 \%$ for the right ventricles, reflecting a slightly greater water content. Of the total adenine nucleotides, the average proportion of ATP remained at the normal level of $84 \%$ in each ventricle. In seven of the eight failing hearts, however, the concentrations of ATP in the right ventricles were from 1 to $14 \%$ lower than in the paired left ventricles $(t=2.76$ and $\mathrm{p}=$

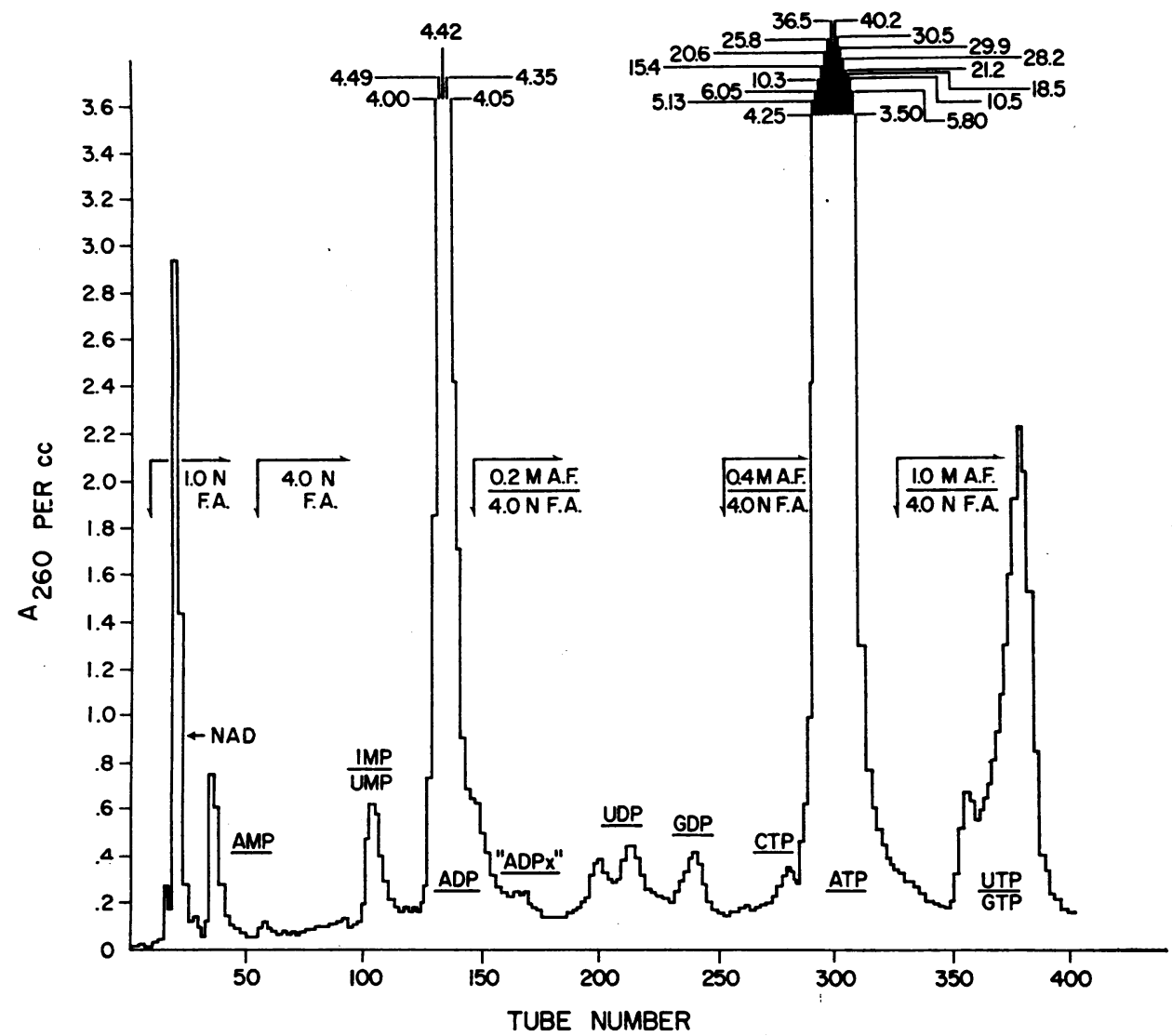

Fig. 1. Normal Phase I chromatogram. Pattern of elution from an ion exchange column of nucleotides present in an acid-soluble extract of a $28-\mathrm{g}$ sample of normal canine right ventricle. Eluting solutions of formic acid (F.A.) and ammonium formate (A.F.) were added in gradated concentrations at the arrows. A260 $=$ absorbance of ultraviolet light at $260 \mathrm{~m} \mu$. Other abbreviations refer to the mono-, di-, or triphosphates of adenosine, inosine, uridine, guanosine, or cytidine. 


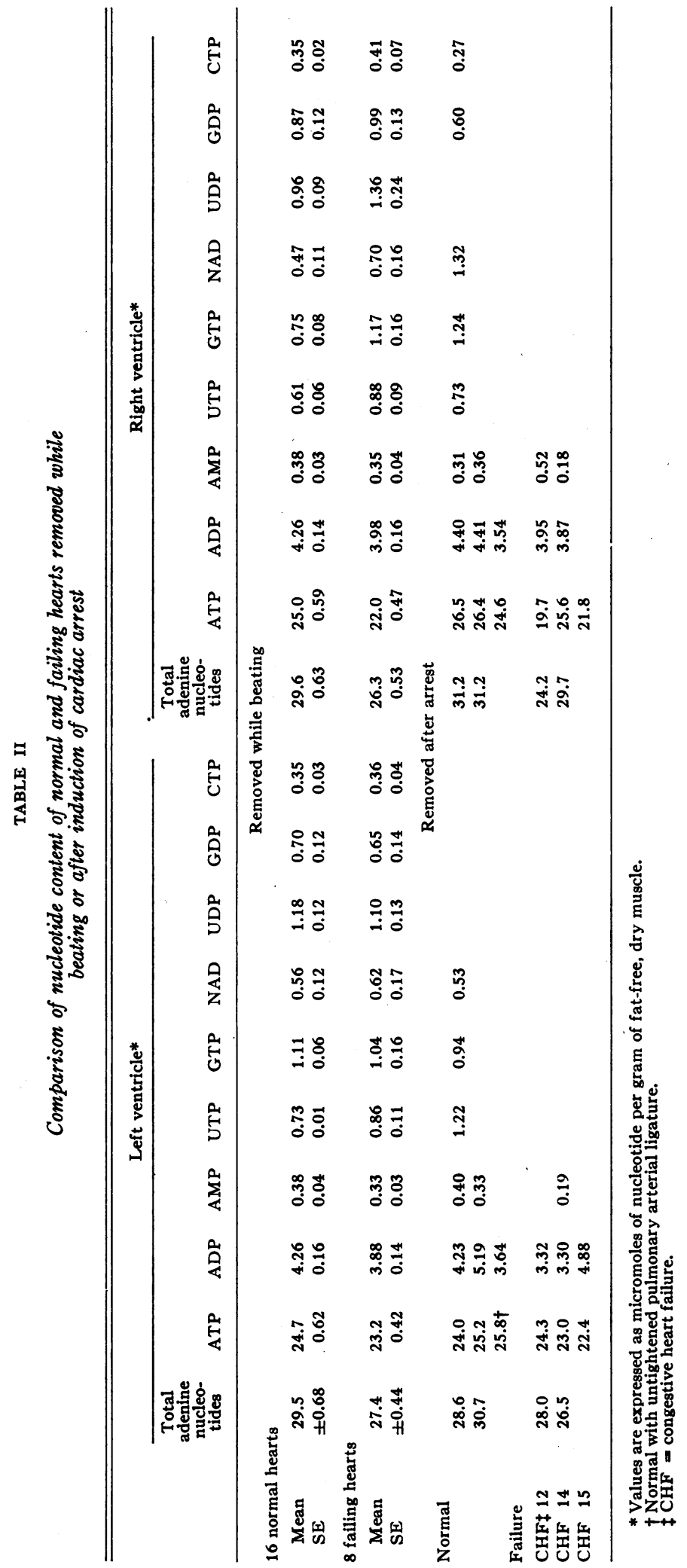


$<0.04)$. When compared as a group with the normal hearts, the failing hearts showed decreases in ATP concentration of $12 \%$ in the right ventricles $(p=<0.001)$ and of $6 \%$ in the left ventricles $(p=<0.03)$. Artifactual hydrolysis of ATP during extirpation of the failing hearts was not a likely cause for these decreases, since there were no significant differences in the inosine-like effluents from the columns or in the concentrations of AMP and ADP. Although levels found for UTP, GTP, and GDP were variably elevated in the failing hearts, the technical limitations in the measurement of these nucleotides made such changes insignificant.

The nucleotide levels in normal or failing hearts removed after induction of cardiac arrest resembled those found in comparable beating hearts, although the numbers were too small for statistical comparison (Table II). One of the three normal hearts removed after induced arrest was from an animal in which an untightened pulmonary arterial ligature had been in place for 3 weeks. The pressure in the right ventricle of this animal was $20 / 0 \mathrm{~mm} \mathrm{Hg}$, and the presence of the ligature did not affect the content of ATP.

\section{Total creatine, free creatine, $\operatorname{Cr} P, P_{i}$, and TASP}

Values found for CrP by the two methods of analysis usually agreed well although the phosphate method gave higher results.

Normal hearts, removed while beating or in arrest. The mean concentrations of $\mathrm{CrP}$ and TASP in the right ventricles were higher than in the left ventricles by 30 to $45 \%$. The $p$ value for the significance of the differences between paired right and left ventricles was $<0.05$. The percentage of total creatine present as $\mathrm{CrP}$ was higher in the right ventricles, but the difference between paired values was significant only in the beating hearts. Induction of cardiac arrest in either normal or failing hearts increased the percentage of total creatine present as $\mathrm{CrP}$, a reflection of decreased hydrolysis of $\mathrm{CrP}$ (Table III ; Table IV and Figure 2).

Hypertrophied hearts, removed in arrest. The mean content of $\mathrm{CrP}$ in the right ventricles was again higher than in the left ventricles, but the difference between paired values was not significant for this smaller group of hearts. Greater

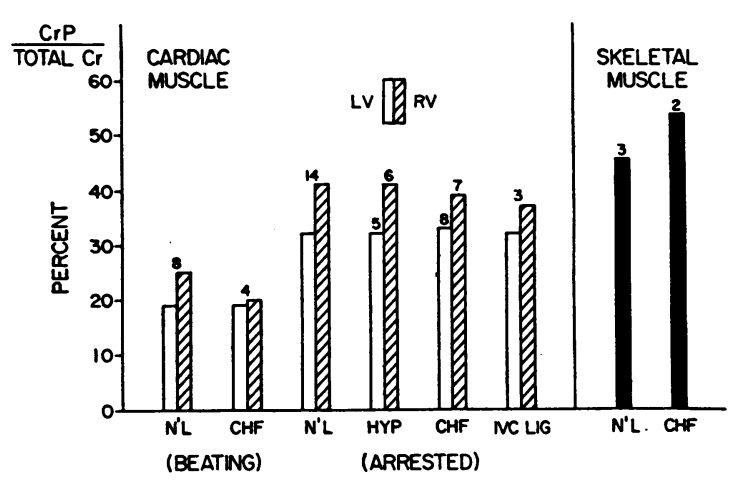

Fig. 2. Percentages of total Creatine present as CREATINE PHOSPHATE IN CARDIAC AND SKELETAL MUSCle FROM VARIOUS PREPARATIONS. The values for $\mathrm{CrP}$ represent averages derived from separate measurements of the creatine base and inorganic phosphate liberated by controlled hydrolysis of heart extracts. The numbers above the columns indicate the number of samples studied. $\mathrm{N}^{\prime} 1=$ normal ; Hyp $=$ right ventricular hypertrophy ; $\mathrm{CHF}=$ congestive heart failure; IVC Lig. = inferior vena caval ligature.

relative hydrolysis of $\mathrm{CrP}$ in the left ventricles was suggested by the higher values found for free $\mathrm{Cr}$ and $\mathrm{P}_{1}$. However, the percentage of total creatine present as $\mathrm{CrP}$ was not significantly lower in the left ventricles (Table IV, B, and Figure 2).

Normal and hypertrophied hearts removed in arrest differed significantly only in content of $P_{i}$ and TASP in the left ventricles (Table IV and Figure 2).

Failing hearts removed while beating. The left ventricles in this group, when compared with normal, beating left ventricles, showed significant decreases in total and free creatine $(-24 \%)$, in $\mathrm{CrP}$ ( $-29 \%$ and $-23 \%$ by the two methods of analysis), and in $\mathrm{P}_{1}(-15 \%)$. The percentage of total $\mathrm{Cr}$ present as $\mathrm{CrP}$ remained the same as in the left ventricles from normal hearts.

The right ventricles showed significant decreases from the normal in total creatine $(-39 \%)$, in free creatine $(-33 \%)$, in $\mathrm{CrP}$ $(-53 \%)$, and in TASP $(-23 \%)$. The percentage of total creatine present as $\mathrm{CrP}$ decreased and reached the levels found for the paired left ventricles in each heart (Table III and Figure 2).

A heart removed while beating from an animal with mild congestive heart failure due to marked tricuspid insufficiency and pulmonary stenosis did not show decreases in content of total creatine 
ARTHUR C. FOX, NORMAN S. WIKLER, AND GEORGE E. REED

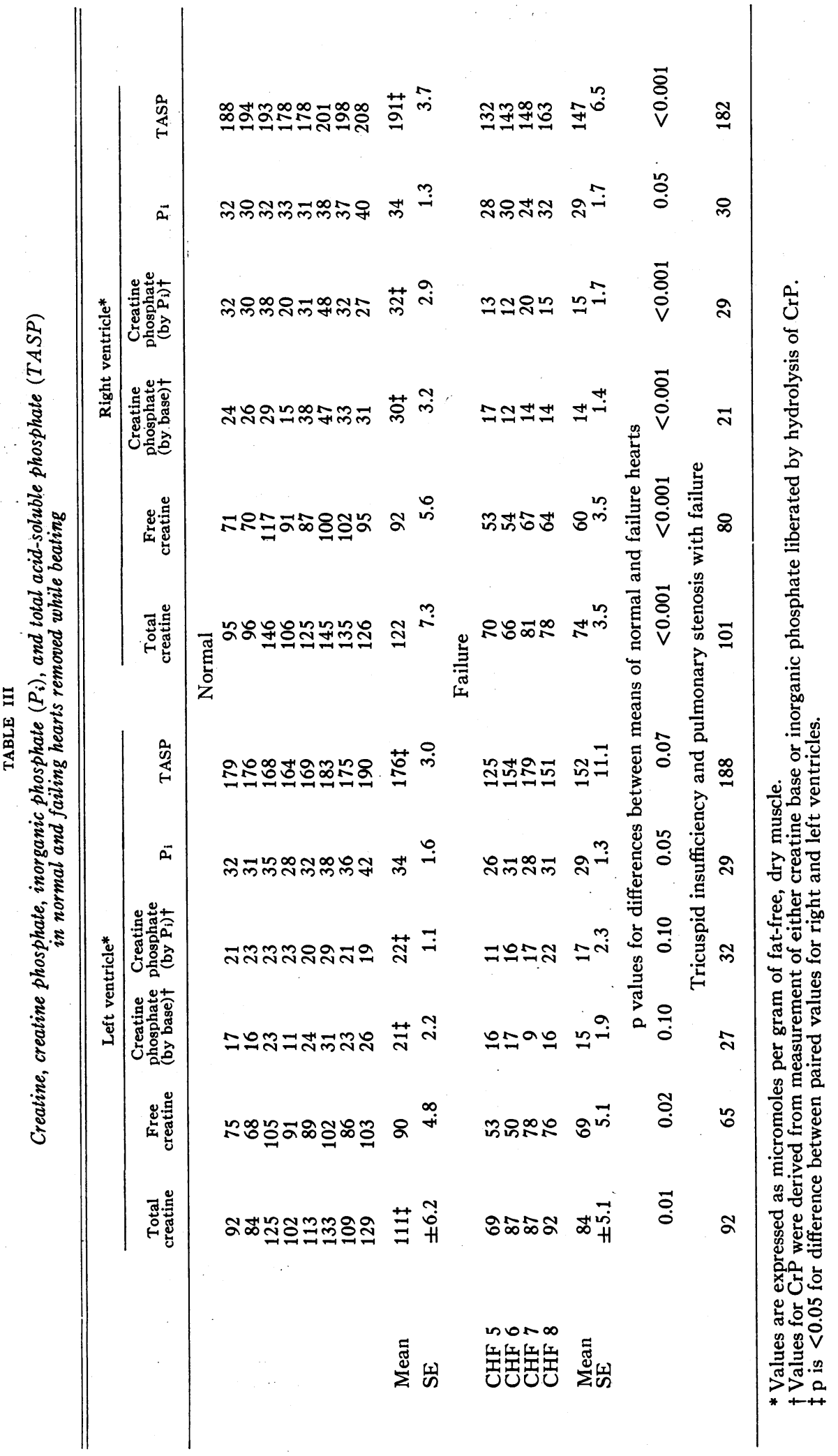


HIGH ENERGY PHOSPHATES DURING HEART FAILURE

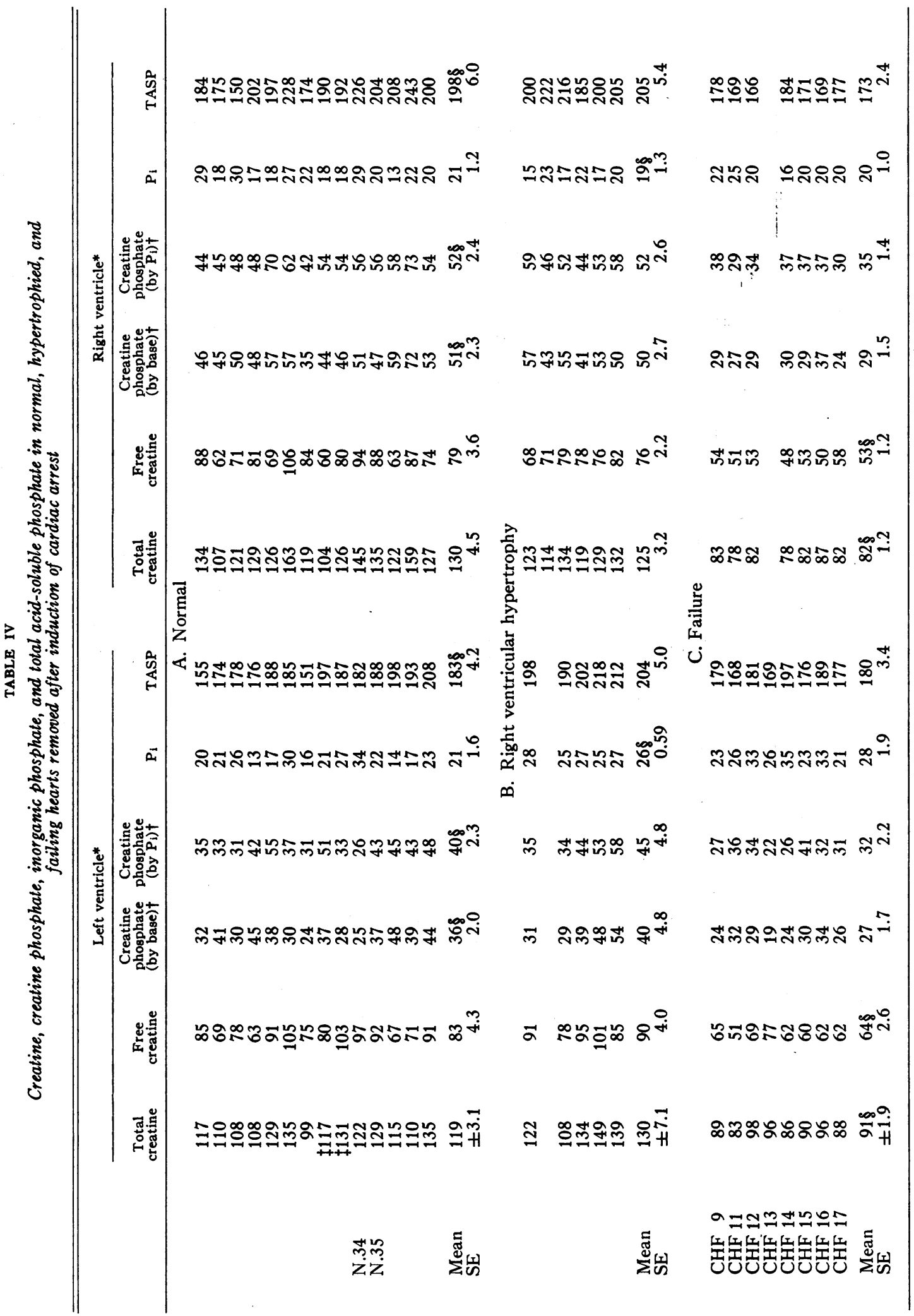




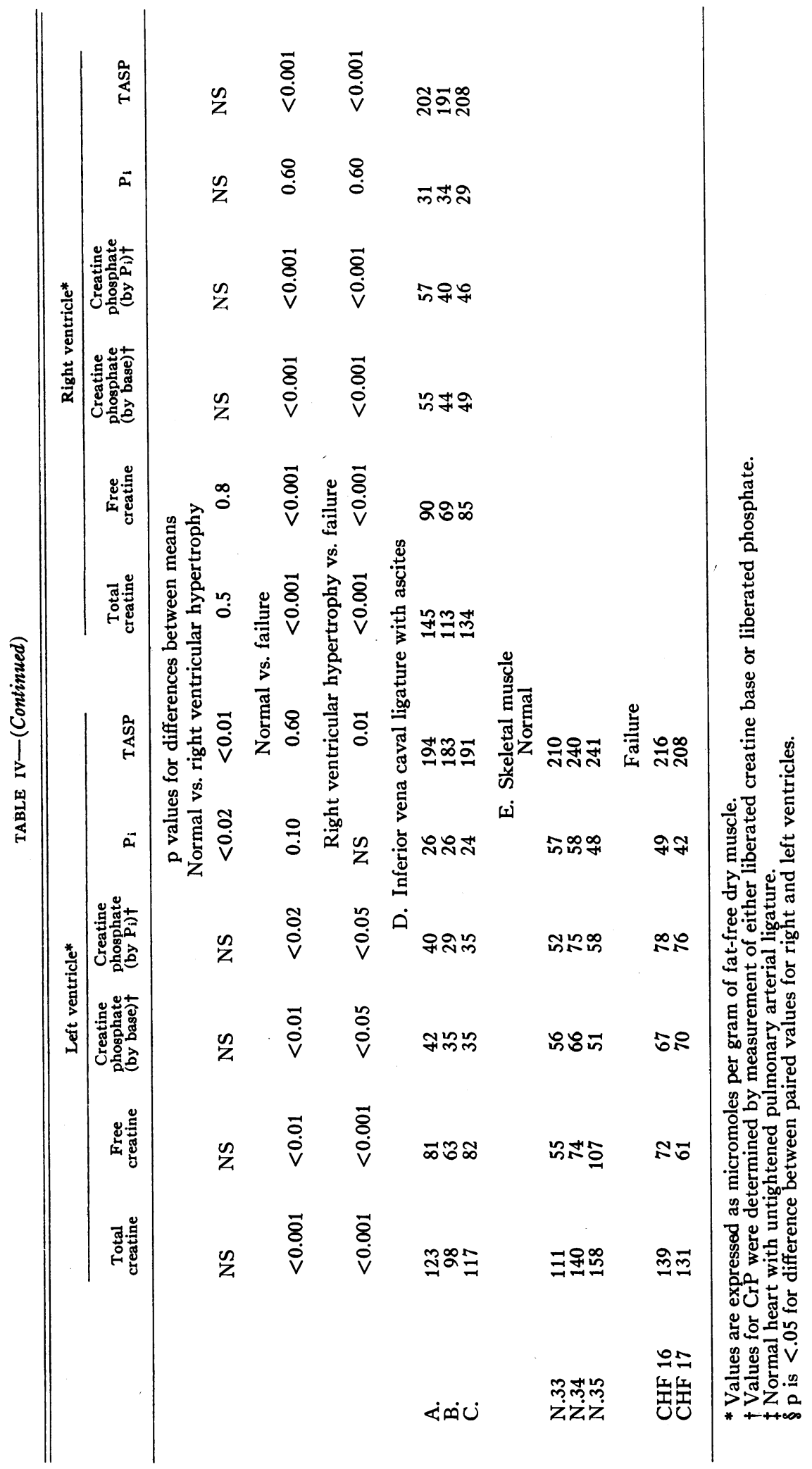


or $\mathrm{CrP}$ as large as those usual in hearts with severe failure due to isolated pulmonary stenosis (Table III).

Failing hearts removed in arrest. The left ventricles in this group showed significant decreases from the normal arrested hearts in total creatine $(-24 \%)$, in free creatine $(-23 \%)$, in $\mathrm{CrP}$ measured by liberated base $(-25 \%)$, and an increase in $\mathrm{P}_{\mathrm{i}}(+20 \%)$.

The right ventricles again showed large decreases in total creatine $(-37 \%)$, free creatine $(-33 \%), \operatorname{CrP}(-43 \%$ and $-33 \%$ by the two methods of analysis), and in TASP $(-13 \%)$. The percentage of total creatine present as $\mathrm{CrP}$ remained the same as in arrested normal hearts, and this value remained higher for each right ventricle than for the corresponding left ventricle.

The differences between the failing and hypertrophied hearts were substantially the same as those between the failing and normal hearts (Table IV and Figure 2).

Partial ligation of the inferior vena cava above the diaphragm in three dogs produced massive ascites, hindquarter edema, liver congestion, and tissue wasting like that seen in the animals with congestive heart failure. Intracardiac pressures were normal. In the right and left ventricles of this small group of animals, the values for total creatine, free creatine, $\mathrm{CrP}, \mathrm{P}_{\mathrm{i}}$, and TASP closely resembled those found for normal, arrested hearts; the relationship between total creatine and $\mathrm{CrP}$ was also normal (Table IV, $\mathrm{D}$, and Figure 2).

Normal skeletal muscles, when compared with normal arrested hearts from the same animals, contained levels of total creatine, free creatine, and $\mathrm{CrP}$ that equaled those in the right ventricles and exceeded those in the left ventricles; levels of $P_{1}$ and TASP in skeletal muscle were higher than in either ventricle. The percentages of total creatine present as $\mathrm{CrP}$ in normal skeletal muscle equaled or exceeded the percentages found for the paired right ventricles. In skeletal muscle samples removed from two animals with congestive heart failure, the content of total creatine, $\mathrm{CrP}, \mathrm{P}_{\mathrm{i}}$, and TASP remained within the normal range, although the hearts from these animals had shown significant decreases in total creatine and $\mathrm{CrP}$ (Table IV, E, and Figure 2).

\section{Discussion}

Previous studies by Davis and associates (30) indicated that in heart failure produced by progressive pulmonary arterial stenosis, the right ventricle was predominantly involved, improvement followed digitalis therapy, and the syndrome resembled severe heart failure in humans with chronic pulmonic stenosis. In the present study, strict criteria were required for the diagnosis of heart failure. The elevated right ventricular end diastolic pressures might have reflected decreased compliance in the walls of the distended and obstructed ventricles $(39,40)$, but the association with breathlessness, circulatory congestion, and elevations in systemic a-v $\mathrm{O}_{2}$ difference indicated a relationship to myocardial failure. Accurate assessment of left ventricular function in the failing hearts was difficult. In terminal right heart failure, a decrease in delivery of blood to the left heart might have decreased coronary perfusion and caused deterioration in function of both ventricles like that produced by acute pulmonary arterial stenosis (41). The absence of dilatation and hypertrophy of the left ventricles, and the rarity of elevations in left ventricular end diastolic pressures during marked systemic circulatory congestion, suggested that despite the clinical appearance of breathlessness the left ventricles were less compromised than the right.

Because of the great lability of ATP and CrP in the presence of the multiple degrading enzymes present in samples of whole tissues, accurate estimates of true in vivo levels are difficult to obtain. Elaborate measures have been devised for instantaneous freezing of small biopsy samples obtained from skeletal muscles during a single twitch (42) or from hearts beating in situ (43). The present study required relatively large samples from both ventricles, and some hydrolysis of highly labile compounds, either $\mathrm{CrP}$ or unidentified intermediate products of oxidative phosphorylation, probably occurred during extirpation. The values obtained for $P_{1}$ served as rough indicators of phosphate bond hydrolysis. The levels of $P_{1}$ found in the arrested hearts were higher than those found in biopsy samples frozen in situ (26), but were equivalent to those found in conventional biopsy samples or in perfused, ar- 
rested hearts $(27,44,45)$. Among the arrested normal and hypertrophied hearts, the values for $\mathrm{CrP}$ in the left ventricles equaled those previously reported $(27,44)$, and the values for the right ventricles were higher. The induction of cardiac arrest allowed greater recovery of $\mathrm{CrP}$, since contractions were not present during extirpation and rigor during freezing was reduced. Levels of ATP in normal hearts removed while beating equaled those reported in other studies using careful techniques. Levels of ATP were not increased by the induction of cardiac arrest before extirpation of the hearts, since ATP is less labile than $\mathrm{CrP}$ and can be transiently maintained by the action of creatine transphosphorylase. Considerable and constant artifactual hydrolysis of ATP to ADP and AMP had not regularly occurred, since the proportions of $\mathrm{ADP}$ to total adenine nucleotides varied among different ventricles. A better indication that "free" $\mathrm{ADP}$ was not entirely derived from hydrolysis of ATP was provided by additional studies with radioactive phosphate, which demonstrated a difference, under certain circumstances, between the degree of labeling of the $\beta$ phosphate of "free" ADP and the $\beta$ phosphate of ATP (46).

$\mathrm{CrP}$ levels in skeletal muscle were only slightly higher than in the arrested normal right ventricles. This finding conflicts with earlier reports that the content of $\mathrm{CrP}$ in skeletal muscle exceeded that in the heart (7). The values found for $P_{i}$ were higher than those found by precise measurements in cat and rabbit skeletal muscle (47), although they agreed well with values found for rat skeletal muscle (48).

Since the values for $\mathrm{CrP}$ and for the percentage of total $\mathrm{Cr}$ present as $\mathrm{CrP}$ in the normal right ventricles were generally higher than in the left ventricle, it was possible that the thicker left ventricles were more slowly arrested or frozen, allowing more time for hydrolysis of $\mathrm{CrP}$. If such hydrolysis had occurred, higher levels of $P_{i}$ and of free creatine should have appeared in the left ventricles. These levels were not increased in the normal left ventricles, but were relatively greater in left ventricles from hypertrophied and failing hearts, suggesting some hydrolysis of $\mathrm{CrP}$.

In the failing right ventricles removed in arrest, the decreased levels of $\mathrm{CrP}$ did not reflect increased hydrolysis of $\mathrm{CrP}$ due to slower freezing of the thick and dilated ventricles, since $P_{1}$ and the percentage of total creatine present as $\mathrm{CrP}$ were not changed from the control values found for normal or hypertrophied right ventricles.

Although the small decreases in concentrations of ATP in the failing right ventricles were significant, the decreases in content of $\mathrm{CrP}$ were clearly more impressive. The importance of $\mathrm{CrP}$ was especially apparent in normal, arrested hearts, where the high energy phosphate accounted for by the phosphagen was twice that in the terminal phosphates of all nucleoside triphosphates. For use in muscular contraction, the high energy phosphates stored in $\mathrm{CrP}$ must be transferred back to ATP, and it has been suggested that cytoplasmic creatine and $\mathrm{CrP}$ may serve to shuttle phosphates between separate compartments of ATP located at the mitochondria and at the myofibrils (3). Since total creatine and $\mathrm{CrP}$ were decreased proportionately in the chronically failing hearts, it is possible that with lower levels of ATP, there may have been a secondary decrease in synthesis of $\mathrm{CrP}$ or an increase in its utilization. The consequent increase in the fraction of free creatine that is readily diffusible (49) might have produced a gradual efflux of creatine from cardiac cells. In the present study, deliberate or accidental production of acute hypoxia during extirpation of normal or failing hearts caused hydrolysis of $\mathrm{CrP}$ but no decreases in total creatine; apparently an intact coronary circulation was required to remove the increased amount of diffusible creatine.

Malnutrition, infection, hypoxia, cardiac failure, and cardiac hypertrophy due to hypoxia have previously been reported to alter myocardial content of creatine $(50,51)$. The first three of these factors were not overtly present in the heart failure animals in this study, and it seemed likely that an abnormality within the failing hearts themselves, rather than changes in the systemic metabolism of creatine, had decreased the myocardial levels of creatine and CrP. The decrease in creatine levels was not caused by congestion of the liver or kidneys, where creatine is principally synthesized $(52,53)$, since concentrations of total creatine and $\mathrm{CrP}$ were normal in the hearts of animals with hepatic and renal congestion produced by ligation of the thoracic inferior vena cava. The decrease in creatine in 
the myocardium did not reflect a general depletion of creatine in all muscles, since skeletal muscle samples from two animals in congestive heart failure contained normal amounts of creatine and CrP. A more specific control might have been provided by comparison of each heart with a constantly active muscle such as the diaphragm, but technical limitations made this impossible.

It is unlikely that the decreases in content of high energy phosphate compounds in the failing hearts reflected a simple physical dilution by an increased proportion of protein in hypertrophied myocardial cells. Failing hearts of the type studied here had previously been shown to contain normal amounts of actomyosin per unit of weight (54), and the hypertrophied control hearts in the present study showed no decreases from normal levels of creatine or $\mathrm{CrP}$.

Since concentrations of UTP, GTP, and CTP did not change significantly, within the wide limits set by the control recovery studies, there were probably no marked alterations during congestive heart failure in the metabolism of these compounds or in their possible role in muscular contraction (55).

The decreases found for ATP and $\mathrm{CrP}$ in this study were similar to those observed by Feinstein in left ventricles from guinea pig hearts failing with aortic stenosis (28). The absence of such changes in other studies $(11,13,16)$ may have been due to limitations in the methods employed for tissue excision, extraction, or analysis or to the fact that the ventricular failure studied was not so severe as that produced by isolated aortic or pulmonary stenosis. The present study indicates that within each terminally failing heart, the more severely stressed right ventricle showed greater decreases in concentrations of ATP and $\mathrm{CrP}$ than did the left ventricle. Although both ventricles might have become chronically hypoxic as a result of decreases in cardiac output and coronary perfusion, the dilated and obstructed right ventricles probably required greater oxygen delivery and utilization to support protracted increases in wall tension and time-tension index.

The decreases found for concentrations of ATP and $\mathrm{CrP}$ cannot definitively be related to the function of the failing heart. The concentrations of these compounds were unchanged in the control group of hypertrophied right ventricles although heart-lung preparations exposed to acute systolic overloading have shown marked decreases (56). The lower levels found for the failing hearts might simply have reflected a new steady state in which the energy sources available for muscular contraction still remained adequate. In vitro models have demonstrated a coupling between mechanical performance of isolated skeletal myofibrils and mitochondrial generation of ATP and $\mathrm{CrP}$ (5). The deterioration in cardiac contractility associated with hypoxia or poisoning with digitalis glycosides has been only variably correlated with decreased steady-state levels of high energy phosphate compounds $(14,24)$, and such results cannot be properly extrapolated to the chronically failing right ventricles in this study. The changes found here were in hearts from animals in which congestive failure of maximal severity was taken as an end point. Producing failure in these preparations was difficult, and hearts for sequential analysis were not available from animals progressing from mild to severe failure. It is therefore not possible to speculate as to whether failure had occurred after a gradual or an abrupt decrease in high energy phosphates or whether the chemical changes were the cause, the result, or even related at all to the severe mechanical failure present.

Nevertheless, the chemical changes found in the chronically failing hearts can be usefully examined in terms of the schema proposed by Siekevitz (6) in an attempt to elucidate the nature of the metabolic steady state present within the cells of the failing hearts. If it is assumed that during severe failure, there is no change in the basic amount of high energy phosphate required to produce a unit of contractile force, the observed falls in high energy phosphates might have reflected any of several possible abnormal metabolic patterns: 1) normal ATPase activity at the myofibrils associated with a primary defect in mitochondrial oxidative phosphorylation, 2) decreased ATPase activity at the myofibrils associated with a greater decrease in mitochondrial oxidative phosphorylation, or 3) increased ATPase activity at the myofibrils and increased delivery of ADP to mitochondria that were unable to respond with augmented ATP production. The myokinase reaction, $2 \mathrm{ADP} \rightleftharpoons \mathrm{ATP}+\mathrm{AMP}$, serves to maintain a constant ratio of ATP to 
ADP when changes occur in the rate of production or utilization of either compound. Estimates of the dominant direction of this reaction at equilibrium might be useful in determining whether production of $\mathrm{ADP}$ was indeed altered by marked changes in myofibrillar ATPase activity. In further studies of normal and failing hearts (46), the status of oxidative phosphorylation was roughly assessed by measuring the rate of incorporation of radioactive phosphate into the terminal phosphate of ATP, and the activity of myokinase was evaluated by determining the rate at which the middle phosphate of ATP was labeled. These studies suggested that the decreases found for concentrations of ATP and $\mathrm{CrP}$ during severe, chronic failure might be most compatible with an altered metabolic state within the myocardial cells in which a decrease in mitochondrial oxidative phosphorylation was associated with a decrease, as noted by others (19), in myofibrillar ATPase activity.

\section{Summary}

Congestive heart failure produced in dogs by progressive stenosis of the main pulmonary artery was more severe than the circulatory congestion produced by a combination of tricuspid insufficiency and mild pulmonary arterial stenosis. Purine and pyrimidine nucleotides, creatine, creatine phosphate, inorganic phosphate, and total acid-soluble phosphate were measured in the right and left ventricles of normal, hypertrophied, and failing hearts extirpated and frozen within 10 seconds.

Among normal hearts, the right and left ventricles contained equal amounts of nucleotides, but the right ventricles contained 30\% more creatine phosphate. Induction of cardiac arrest before extirpation of the hearts improved recovery of creatine phosphate. Hearts with right ventricular hypertrophy unassociated with failure showed no changes in content of creatine or creatine phosphate.

With chronic heart failure due to pulmonary arterial stenosis, right ventricles showed decreases in adenosine triphosphate of $-12 \%$, in creatine phosphate of -33 and $-43 \%$ by two methods, and in total creatine of $-37 \%$. The decreases in these compounds were much less pronounced in the paired left ventricles. Nucleoside triphosphates other than adenosine triphosphate were not changed significantly. Hearts from animals with circulatory congestion produced by ligation of the thoracic inferior vena cava, and skeletal muscle samples from animals in heart failure, did not show decreases from the normal levels of creatine or creatine phosphate.

The chemical changes found may or may not have had a relationship to the mechanical performance of the failing heart, but might reflect an altered metabolic steady state within the myocardial cells.

\section{Acknowledgments}

The authors wish to thank Mrs. Marjorie Gable, Mrs. Madeline Britman, and Miss Jean Engel for their technical help.

\section{References}

1. Mommaerts, W. F. H. M., A. J. Brady, and B. C. Abbott. Major problems in muscle physiology. Ann. Rev. Physiol. 1961, 23, 529.

2. Davies, R. E., D. Cain, and A. M. Delluva. The energy supply for muscular contraction. Ann. N. Y. Acad. Sci. 1959, 81, 468.

3. Carlson, F. D., and A. Siger. The mechano-chemistry of muscular contraction. J. gen. Physiol. 1960, 44, 33.

4. Chance, B. The response of mitochondria to muscular contraction. Ann. N. Y. Acad. Sci. 1959, 81, 477.

5. Watanabe, S., and L. Packer. Oxidative phosphorylation of cardiac mitochondria in contraction of glycerol-treated fibers of psoas muscle. J. biol. Chem. 1961, 236, 1201.

6. Siekevitz, P. Oxidative phosphorylation in muscle mitochondria and its possible regulation. Ann. N. Y. Acad. Sci. 1959, 72, 500.

7. Olson, R. E. Physiology of cardiac muscle in Handbook of Physiology. Washington, Amer. Physiol. Soc., 1962, vol. 1, p. 199.

8. Blain, J. M., H. Schafer, A. L. Siegel, and R. J. Bing. Studies on myocardial metabolism. VI. Myocardial metabolism in congestive heart failure. Amer. J. Med. 1956, 20, 820.

9. Goodale, W. T., R. E. Olson, and D. B. Hackel. Myocardial glucose, lactate and pyruvate metabolism of normal and failing hearts studied by coronary venous catheterization in man. Fed. Proc. 1950, 9, 49.

10. Bing, R. J., E. Siegel, A. Vitale, F. Balboni, E. Sparks, M. Taeschler, M. Klapper, and S. Edwards. Metabolic studies on the human heart in vivo; 1 . Studies on carbohydrate metabolism of the human heart. Amer. J. Med. 1953, 15, 284. 
11. Olson, R. E., and D. A. Piatnek. Conservation of energy in cardiac muscle. Ann. N. Y. Acad. Sci. 1959, 72, 466.

12. Katz, L. N., H. Feinberg, and A. B. Schaffer. Hemodynamic aspects of congestive heart failure. Circulation 1960, 21, 95.

13. Wollenberger, A. The energy metabolism of the failing heart and the metabolic action of the cardiac glycosides. Pharmacol. Rev. 1949, 1, 311.

14. Furchgott, R. F., and T. de Gubareff. The high energy phosphate content of cardiac muscle under various experimental conditions which alter contractile strength. J. Pharmacol. exp. Ther. 1958, 124, 203.

15. Lee, K. S., D. H. Yu, and R. Burstein. The effect of ouabain on the oxygen consumption, the high energy phosphates and the contractility of the cat papillary muscle. J. Pharmacol. exp. Ther. 1960, 129, 115.

16. Buckley, N. M., and K. K. Tsuboi. Cardiac nucleotides and derivatives in acute and chronic ventricular failure of the dog heart. Circulat. Res. 1961, 9, 618.

17. Benson, E. S., B. E. Hallaway, and C. E. Turback. Contractile properties of glycerol-extracted muscle bundles from the chronically failing canine heart. Circulat. Res. 1958, 6, 122.

18. Kako, K., and R. J. Bing. Contractility of actomyosin bands prepared from normal and failing human hearts. J. clin. Invest. 1958, 37, 465.

19. Alpert, N. R., and M. S. Gordon. Myofibrillar adenosine triphosphatase activity in congestive heart failure. Amer. J. Physiol. 1962, 202, 940.

20. Davis, J. O., W. R. Carroll, M. Trapasso, and N. A. Yankopoulos. Chemical characterization of cardiac myosin from normal dogs and from dogs with chronic congestive heart failure. J. clin. Invest. 1960, 39, 1463.

21. Olson, R. E. The contractile proteins of heart muscle. Amer. J. Med. 1961, 30, 692.

22. Wollenberger, A., and W. Schulze. Mitochondrial alterations in the myocardium of dogs with aortic stenosis. J. biophys. biochem. Cytol. 1961, 10, 285.

23. Gertler, M. M. Differences in efficiency of energy transfer in mitochondrial systems derived from normal and failing hearts. Proc. Soc. exp. Biol. (N. Y.) 1961, 106, 109.

24. Schwartz, A., and K. S. Lee. Study of heart mitochondria and glycolytic metabolism in experimentally induced cardiac failure. Circulat. Res. 1962, 10, 321.

25. Hurlbert, R. B., H. Schmitz, A. F. Brumm, and V. R. Potter. Nucleotide metabolism II. Chromatographic separation of acid-soluble nucleotides. J. biol. Chem. 1954, 209, 23.

26. Wollenberger, A., E.-G. Krause, and B. E. Wahler. Über den tatsächlichen Orthophosphat- und N-Phos- phorylkreatingehalt des Säugetierherzens. Pflügers. Arch. ges. Physiol. 1960, 270, 413.

27. Fawaz, G., and E. Manoukian. Steady-state level of phosphocreatine in the heart. Circulat. Res. 1962, 11, 115.

28. Feinstein, M. B. Effects of experimental congestive heart failure, ouabain and asphyxia on the highenergy phosphate content and creatine content of the guinea pig heart. Circulat. Res. 1962, 10, 333.

29. Barger, A. C., G. S. Richardson, and B. B. Roe. A method for producing chronic cardiac failure in dogs. Proc. Soc. exp. Biol. (N. Y.) 1950, 73, 113.

30. Davis, J. O., R. E. Hyatt, and D. S. Howell. Rightsided congestive heart failure in dogs produced by controlled progressive constriction of the pulmonary artery. Circulat. Res. 1955, 3, 252.

31. Lee, Y. C. P., R. A. DeWall, and M. B. Visscher. State of creatine in mammalian heart muscle. Amer. J. Physiol. 1960, 198, 855.

32. Lilienthal, J. L., Jr., K. L. Zierler, B. P. Folk, R. Buka, and M. J. Riley. A reference base and system for analysis of muscle constituents. J. biol. Chem. 1950, 182, 501.

33. Oken, D. E., and R. J. Boucek. Quantitation of collagen in human myocardium. Circulat. Res. 1957, 5, 357.

34. Deutsch, A., and R. Nilsson. Separation of adenosine and inosine phosphates by paper chromatography. Acta chem. scand. 1953, 7, 858.

35. Hawk, P. B., B. L. Oser, and W. H. Summerson. Practical Physiological Chemistry, 13th ed. New York, Blakiston, 1954, p. 953.

36. Furchgott, R. F., and T. de Gubareff. The determination of inorganic phosphate and creatine phosphate in tissue extracts. J. biol. Chem. 1956, 223, 377.

37. Ennor, A. H., and H. Rosenberg. The determination and distribution of phosphocreatine in animal tissues. Biochem. J. 1952, 51, 606.

38. Finlayson, J. K., M. N. Luria, and P. N. Yu. Some circulatory effects of thoracotomy and intermittent positive pressure respiration in dogs. Circulat. Res. 1961, 9, 862.

39. Braunwald, E., S. J. Sarnoff, R. B. Case, W. N. Stainsby, and G. H. Welch, Jr. Hemodynamic determinants of coronary flow: effect of changes in aortic pressure and cardiac output on the relationship between myocardial oxygen consumption and coronary flow. Amer. J. Physiol. 1958, 192, 157.

40. Braunwald, E., and J. Ross, Jr. The ventricular end diastolic pressure. Appraisal of its value in the recognition of ventricular failure in man. Amer. J. Med. 1963, 34, 147.

41. Bacaner, M., J. E. Connolly, and D. Bruns. The coronary blood flow as a critical determinant of cardiac performance and cardiac size. Amer. J. Med. 1961, 30, 392. 
42. Mommaerts, W. F. H. M. Investigation of the presumed breakdown of adenosine-triphosphate and phosphocreatine during a single muscle twitch. Amer. J. Physiol. 1955, 182, 585.

43. Wollenberger, A., O. Ristau, and G. Schoffa. Eine einfache Technik der extrem schnellen Abkuhlung gröserer Gewebestucke. Pflügers Arch. ges. Physiol. 1960, 270, 399.

44. Gott, V. L., M. Bartlett, D. M. Long, C. W. Lillehei, and J. A. Johnson. Myocardial energy substances in the dog heart during potassium and hypothermic arrest. J. appl. Physiol. 1962, 17, 815.

45. Benson, E. S., G. T. Evans, B. E. Hallaway, C. Phibbs, and E. F. Freier. Myocardial creatine phosphate and nucleotides in anoxic cardiac arrest and recovery. Amer. J. Physiol. 1961, 201, 687.

46. Fox, A. C., and G. E. Reed. In preparation.

47. Sacks, J., and R. S. Fulford. Free and bound orthophosphate and phosphocreatine in muscle. Arch. Biochem. 1964, 104, 423.

48. Threlfall, C. J. An analytical procedure for the acid-soluble phosphorous compounds in rat-skeletal muscle. Biochem. J. 1957, 65, 694.

49. Lee, Y. C. P., and M. B. Visscher. On the state of creatine in heart muscle. Proc. nat. Acad. Sci. (Wash.) 1961, 47, 1510.
50. Myers, V. C. Some chemical changes in the myocardium accompanying heart failure. Bull. N. Y. Acad. Med. 1942, 18, 303.

51. Edman, C. D., N. P. Silvers, E. C. Gangloff, and R. F. Krause. Creatine, creatine phosphate, and creatinine levels in hypoxia hypertrophied rat hearts. Amer. J. Physiol. 1963, 204, 1005.

52. Ennor, A. H., and J. F. Morrison. Biochemistry of the phosphagens and related guanidines. Physiol. Rev. 1958, 38, 631.

53. Gerber, G. B., G. Gerber, T. R. Koszalka, and L. L. Miller. The rate of creatine synthesis in the isolated, perfused rat liver. J. biol. Chem. 1962, 237, 2246.

54. Davis, J. O., M. Trapasso, and N. A. Yankopoulos. Studies of actomyosin from cardiac muscle of dogs with experimental congestive heart failure. Circulat. Res. 1959, 7, 957.

55. Ranney, R. E. Biochemical characteristics of glycerol extracted myocardial fibers. Amer. J. Physiol. 1955, 183, 197.

56. Hochrein, H., and H. J. Döring. Die energiereichen Phosphate des Myokards bei Variation der Belastungsbedingungen. Pflügers Arch. ges. Physiol. 1960, 271, 548.

\section{SPECIAL NOTICE TO SUBSCRIBERS}

Post Offices will no longer forward the Journal when you move.

Please notify The Journal of Clinical Investigation, Business Office, 10 Stoughton Street, Boston, Mass. 02118, at once when you have a change of address, and do not omit the $\mathrm{Zip}$ Code number. 